\title{
Child maltreatment and mental health problems in adulthood: birth cohort study
}

Steve Kisely, Amanuel Alemu Abajobir, Ryan Mills, Lane Strathearn, Alexandra Clavarino and Jake Moses Najman

\section{Background}

Retrospective studies have shown a high association between child abuse and subsequent psychiatric morbidity. Prospective studies are rarer.

\section{Aims}

To examine, using a prospective record-linkage analysis, whether substantiated child maltreatment is associated with adverse psychological outcomes in early adulthood.

\section{Method}

The participants were 3778 mother and child pairs enrolled in a population-based birth cohort study in Brisbane, Australia. Exposure to suspected child maltreatment was measured by linkage with state child protection agency data. The primary outcomes were the internalising and externalising scales of the Youth Self-Report and the Centre for Epidemiological Studies-Depression scales (CES-D) at approximately 21 years of age. A subset completed the Composite International Diagnostic Interview-Auto version (CIDI-Auto).

\section{Results}

In total, 171 (4.5\%) participants had a history of substantiated child maltreatment, most commonly emotional abuse $(n=91)$, followed by physical abuse $(n=78)$, neglect $(n=73)$ and sexual abuse $(n=54)$. After adjustment for potential confounders, depressive symptoms on the CES-D, as well as internalising and externalising behaviours were strongly associated with substantiated abuse in all forms, except sexual abuse. The results for the subset of the sample who completed the CIDIAuto were less clear. Anxiety, especially post-traumatic stress disorder, showed the strongest association whereas the findings for depressive disorder were equivocal. However, across all diagnostic categories, emotional abuse and neglect, as well as multiple forms of abuse, showed a consistent association.

\section{Conclusions}

Child maltreatment, particularly neglect and emotional abuse, has serious adverse effects on early adult mental health. These two warrant the attention given to other forms of child maltreatment. Children experiencing more than one type of maltreatment are at particular risk.

\section{Declaration of interest}

None.

\section{Keywords}

Child abuse; depressive disorders; post-traumatic stress disorder; anxiety disorders.

\section{Copyright and usage}

(c) The Royal College of Psychiatrists 2018.
Despite the potential for negative consequences, comparatively little is known about the impact on health of specific and multiple forms of substantiated childhood maltreatment. ${ }^{1,2}$ Evidence from crosssectional studies suggests that children who are exposed to sexual, physical and emotional abuse and/or neglect are more likely to experience mental health problems than those not exposed. ${ }^{3}$ However, findings from these studies are limited by the potential for recall bias, ${ }^{4,5}$ their focus on a few specific types of childhood maltreatment (despite the fact that most childhood maltreatment experiences co-occur), ${ }^{6}$ and the use of clinical rather than population samples. Few previous studies have controlled for factors that may predispose to both child maltreatment and later adverse health outcomes. These include familial sociodemographic characteristics, ${ }^{7}$ psychopathologies ${ }^{8}$ and environmental disadvantages. ${ }^{7}$ Moreover, retrospective reports of life course adverse exposures can change over time depending on resilience, recovery ${ }^{9}$ and severity of the exposures. Finally, in cross-sectional studies, childhood maltreatment might be both a cause and an effect.

Longitudinal studies offer evidence that is more robust but they have generally been narrow in focus. This includes participants that are limited to females, ${ }^{10}$ or particular types of child maltreatment (for example sexual abuse), ${ }^{11,12}$ or people in treatment and/or identified as being at high risk. ${ }^{13-15}$ In addition, some longitudinal studies have used retrospective recall of abuse rather than prospectively collected data. ${ }^{16-18}$ Where prospective data have been collected, child maltreatment has been considered as a whole without any comparisons between different types. ${ }^{18-20}$ One New Zealand study prospectively collected observations by staff of maternal rejection when the child was 3 years old, as well as parent-reported harsh discipline at ages 7 and 9 . Abuse was categorised by severity rather than type and based on a composite measure derived from both retrospective and prospective data. ${ }^{18}$ Another relied on whether participants had been entered on to the national electronic database of the New Zealand's Child, Youth and Family agency but, again, did not specify the category of abuse. ${ }^{20}$ The most consistent prospective results concern adolescents where substantiated cases of neglect, emotional, sexual and physical abuse were associated with internalising and other mental health problems at 14 years old. ${ }^{21}$ The effects on adults were not studied.

\section{Method}

This longitudinal birth cohort study investigated the mental health outcomes of young adults who experienced substantiated childhood maltreatment using prospective data from the Mater-University of Queensland Study of Pregnancy (MUSP). ${ }^{22}$ MUSP is one of a few longitudinal studies that has investigated the long-term consequences of childhood maltreatment, while controlling for possible postnatal, childhood, adolescent and adult confounders. ${ }^{21}$ The design also permitted the comparison of different types of childhood maltreatment, as well as the frequency and age at which it occurred. ${ }^{23}$ The University of Queensland Behavioural and Social Sciences Ethical Review Committee approved the protocol and we followed STROBE guidelines for the conduct of cohort 
studies (STrengthening the Reporting of OBservational studies in Epidemiology). ${ }^{24}$

\section{Data sources}

Between 1981 and 1983, 8556 consecutive pregnant women attending the Mater Misericordiae Mothers' Hospital for their first prenatal visit were invited to participate. ${ }^{22}$ The final cohort numbered 7223 mother and infant pairs, which included only consenting participants who delivered live, singleton infants at the study hospital. Twins $(n=60)$ and triplets $(n=1)$ were excluded from the MUSP cohort, as these children shared both a genetic background and multiple social characteristics. Given the small numbers involved and the need to control for multiple factors in any analysis, it was impractical to include them in the overall cohort.

At the first visit, the women completed a detailed questionnaire covering topics such as demographic background, personal health and their feelings about the pregnancy. The mothers and children were further assessed when the children were aged 3-5 days, 6 months, 5 years, 14 years and 21 years. The follow-up rate of the children for the main questionnaire at 21 years was $52.3 \%$.

\section{Child maltreatment measures}

We used data on substantiated cases of child maltreatment reported to Queensland's child protection agency, the Department of Families, Youth and Community Care (DFYCC). These data were linked anonymously to the MUSP longitudinal data using an identification number. ${ }^{25}$ Each time DFYCC received information about possible child maltreatment, a child protection notification was recorded and an investigation commenced. The exposure to agency-recorded child sexual abuse was defined as one or more reports to DFYCC that were substantiated prior to September 2000 , at which time the members of the cohort were approximately 16 years old.

\section{Psychiatric outcome measures}

We used three assessment tools. Our primary outcome measure was the Centre for Epidemiological Studies-Depression (CES-D) scale, ${ }^{26}$ a 20-item measure of depressive symptoms in the previous week. Possible responses range from 0 to 3 for each item (0, rarely or none of the time; 1 , some or little of the time; 2 , moderately or much of the time; 3 , most or almost all the time). A score of 16 or greater shows good sensitivity and specificity, as well high internal consistency, in indicating the possibility of clinical depression. ${ }^{26}$

We measured internalising and externalising symptoms using scales from the Achenbach Youth Self-Report (YSR) questionnaire. ${ }^{27}$ These scales are widely used in child and adolescent psychological research with most significant adolescent psychological symptoms included in one or the other scale. The internalising scale (31 items) is the total of the subscales of withdrawal, anxious/depressed and somatic symptoms, and the externalising scale (30 items) is the total of aggression and delinquency symptoms.

Finally, the presence of DSM-IV diagnoses ${ }^{28}$ was measured using the World Health Organization Composite International Diagnostic Interview (CIDI), ${ }^{29}$ a diagnostic interview schedule based on DSM-IV criteria. We used the CIDI-Auto, a computerised protocol that has been shown to perform satisfactorily when compared with personal interview. ${ }^{29}$ The outcomes of interest were depression (major depression and dysthymic disorder), anxiety disorders (generalised anxiety disorder, panic disorder, agoraphobia, social phobia and specific phobias), and post-traumatic stress disorder (PTSD). We also looked at a combined outcome of any of the above disorders. We considered both lifetime symptoms, and those within the previous 12 months.

\section{Potential confounding variables}

We adjusted for sociodemographic variables that could be potential confounders between child maltreatment and poor psychological outcomes at the 21-year follow-up. These included the following variables that were measured on entry to the study: gender of the child; parental ethnicity; maternal age; mother's relationship status; family income at the time of study entry (first prenatal visit) and maternal education status at study entry. ${ }^{19}$ To these, we added the following potential mediating or modifying variables that were collected at the 21-year follow-up: the young person's income, their educational achievement, marital status and characteristics of their neighbourhood. The latter was assessed by asking how much of the following were a problem in the area where they lived using nine items $(\alpha=0.81) .^{30}$ These items were the presence of vandalism/graffiti, house burglaries, car stealing, violence in the streets, unemployment, noisy and/or reckless driving, alcohol and drug misuse and school truancy. The measure had five scales ranging from 1 , do not know to 5, a major problem. The top decile of mean scores was taken to represent a 'high' residential problem area, and the variable dichotomised into normal and high.

\section{Statistical analysis}

We initially performed a cross-tabulation of the association between agency-substantiated maltreatment and psychiatric outcomes as measured by the CES-D, YSR and CIDI-Auto. We considered the overall category of substantiated abuse, as well as each of the following subtypes: emotional, physical and sexual abuse, as well as neglect. We undertook a sensitivity analysis of the effect of restricting cases to those substantiated by 5 years old. We also used a combined variable of emotional abuse or neglect, given the overlap between the DFYCC definitions of both types. Emotional abuse included acts that led to 'emotional deprivation', and the definition of neglect included the failure to provide children with the conditions for 'healthy...emotional development'. As a result, failure to provide affection and psychological nurturing (emotional neglect) could result in categorisation as either neglect or emotional abuse. In addition, in recognition that types of abuse are rarely exclusive, we also studied the effect of more than one substantiated report, as well as the effect of multiple types of substantiated abuse.

We then used multivariate multiple or logistic regression analysis to control for the known or suspected confounding and moderating variables. Missing data were handled by listwise deletion. We also undertook a propensity analysis of adding a variable representing the baseline confounders across the whole cohort at risk of exposure ( $n=7214$ for agency-substantiated child maltreatment) to identify possible effects of differential attrition on the association with psychiatric outcomes at 21 years old. ${ }^{31}$ This particularly applied to the results from the CIDI-Auto interview given the instrument was not administered to the entire remaining cohort. Finally, we performed a sensitivity analysis of the effect of adjusting only for baseline characteristics, as some of the variables at the 21year follow-up could have been associated with both psychiatric outcomes and child maltreatment.

\section{Results}

Of the 7223 mother and child dyads in the original cohort, statutory agency child protection history was available for 7214 . For eight pairs, there was insufficient demographic data to positively identify the child protection record. One participant was inadvertently 
Table 1 Mean Achenbach Youth Self-Report scores ${ }^{a}$

\begin{tabular}{|c|c|c|c|c|c|c|c|c|}
\hline & \multicolumn{4}{|c|}{ Mean internalising score } & \multicolumn{4}{|c|}{ Mean externalising score } \\
\hline & Unadjusted & $P$ & Adjusted & $P$ & Unadjusted & $P$ & Adjusted & $P$ \\
\hline No maltreatment & 0.00 & & & & 0.00 & & & \\
\hline Any substantiation & 2.03 (0.74 to 3.32) & $<0.001$ & 1.31 (0.18 to 2.61) & 0.047 & 2.16 (1.10 to 3.22$)$ & $<0.001$ & 1.76 (0.70 to 2.82) & 0.001 \\
\hline Physical abuse & 2.22 (0.35 to 4.09$)$ & 0.021 & $1.58(-0.29$ to 3.46$)$ & 0.098 & 2.55 (1.02 to 4.09$)$ & $<0.001$ & 1.84 (0.30 to 3.39) & 0.019 \\
\hline Emotional abuse & 3.59 (1.86 to 5.33$)$ & $<0.001$ & 3.10 (1.35 to 4.85$)$ & 0.001 & 3.39 (1.96 to 4.82$)$ & $<0.001$ & 2.92 (1.48 to 4.35$)$ & $<0.001$ \\
\hline Neglect & 3.68 (1.73 to 5.62$)$ & $<0.001$ & 2.73 (0.77 to 4.69$)$ & 0.006 & 3.72 (2.13 to 5.32$)$ & $<0.001$ & 3.10 (1.49 to 4.71$)$ & $<0.001$ \\
\hline Sexual abuse & $1.07(-1.18$ to 3.31$)$ & 0.35 & $0.05(-2.27$ to 2.16$)$ & 0.96 & $0.06(-1.79$ to 1.91$)$ & 0.95 & $0.25(-1.56$ to 2.07$)$ & 0.78 \\
\hline $\begin{array}{l}\text { More than one substantiation } \\
\text { event }\end{array}$ & 1.58 (1.36 to 4.41$)$ & $<0.001$ & 1.06 (0.18 to 1.95$)$ & 0.018 & 1.59 (0.87 to 2.31) & $<0.001$ & 1.36 (0.63 to 2.08) & $<0.001$ \\
\hline Emotional abuse + neglect & 2.89 (1.36 to 4.41$)$ & $<0.001$ & 2.99 (0.81 to 3.87) & 0.003 & 3.30 (2.05 to 4.55$)$ & $<0.001$ & 2.83 (1.57 to 4.09$)$ & $<0.001$ \\
\hline Multiple abuse types & 3.96 (2.18 to 5.73 ) & $<0.001$ & 3.03 (1.55 to 4.50$)$ & $<0.001$ & 3.62 (2.16 to 5.08 ) & $<0.001$ & 3.03 (1.55 to 4.50$)$ & $<0.001$ \\
\hline
\end{tabular}

omitted from the child protection search. The proportion of children completing the main questionnaire at the 21-year follow-up was $52.4 \%$ (3778 of 7214), of whom 1988 (52.6\%) were male and 3394 (89.8\%) White. Just under 4\% were Indigenous Australians. Only $10 \%$ were not in a relationship $(n=389)$. Of this sample, 2508 (67\%) completed the CIDI-Auto interview. Loss to followup was greater among participants with markers of socioeconomic and other forms of disadvantage. ${ }^{32}$ Further, there was increased attrition among families who had been subject to reported child maltreatment. ${ }^{32}$

\section{Child maltreatment}

Of the 3778 young people at 21-year follow-up, 171 (4.5\%) had a history of substantiated maltreatment by the age of 16 years old. Of these, the cases of 61 individuals were notified by 5 years old. The most common was emotional abuse $(n=91)$, followed by physical abuse $(n=78)$, neglect $(n=73)$ and sexual abuse $(n=54)$. In total 120 had either emotional abuse or neglect (3.2\%). A total of $86(2.3 \%)$ had a history of multiple types of substantiated abuse, and 65 more than one substantiated report $(1.7 \%)$. The rates of any substantiated child maltreatment were associated with measures of social disadvantage. Participants from an Indigenous background $\left(\chi^{2}(\right.$ d.f. $\left.=1)=9.7, P=0.002\right)$, those who were receiving less than $\$ 159$ per week $\left(\chi^{2}(\right.$ d.f. $\left.=1)=29.20, P<0.0001\right)$ or had never been married $\left(\chi^{2}(\right.$ d.f. $\left.=1)=9.40, P=0.002\right)$ were more likely to have been exposed to child maltreatment. The same applied to participants whose mothers had an incomplete high school education $\left(\chi^{2}(\right.$ d.f. $\left.=1)=37.42, P<0.0001\right)$ or parents were not living together at the time of their birth $\left(\chi^{2}(\right.$ d.f. $\left.=1)=42.76, P<0.0001\right)$ and/or a low income. By contrast, participants who had reached tertiary education were less likely to have a history of child maltreatment $\left(\chi^{2}(\right.$ d.f. $\left.=1)=4.23, P=0.002\right)$. These associations were similar across all forms of substantiated child maltreatment.

\section{Depression as measured by the CES-D scale}

Just under $24 \%$ of the sample had a score of 16 or greater on the CES-D scale. Supplementary Table 1, available at https://doi.org/ $10.1192 /$ bjp.2018.207, compares the results by a range of sociodemographic and child maltreatment variables adjusted for all the other variables in the table. Women, people on a low income and those who were living in a socially deprived area were more likely to have clinical depression as measured by the CES-D scale. By contrast, those whose parents were living together at birth, or who had reached tertiary level education had reduced odds of depression. After adjusting for all the above sociodemographic factors, we found that young people who had experienced all forms of substantiated abuse, particularly substantiation for two or more subtypes, were $80 \%$ more likely to report depression (Supplementary Table 1). The only exception was sexual abuse.

\section{Internalising and externalising}

Data from the YASR were available on up to 3725 participants. The mean internalising raw score for the whole cohort was 10.76 (s.d. = 8.29), and the externalising score was 9.49 (s.d. $=6.81$ ). Both before and after adjustment for sociodemographic covariates, substantiated maltreatment was significantly associated with both internalising and externalising behaviour at 21 years of age (Table 1 and Supplementary Table 2). Similarly, physical abuse, neglect and emotional abuse were all associated with internalising and externalising behaviour both before and after adjustment (Table 1 and Supplementary Table 2). The same applied to more than one substantiated event and multiple types of abuse (Table 1 and Supplementary Table 2). Again, the only exception was sexual abuse (Table 1 and Supplementary Table 2). In addition, physical abuse and internalising were not significantly associated after adjustment (Table 1).

\section{Common mental disorders as measured by CIDI-Auto}

Of the total sample at follow-up, 2508 (67\%) completed the CIDIAuto interview. In the previous 12 months, 273 participants (11\%) reported a depressive disorder, 486 (19\%) an anxiety disorder and 111 (4\%) PTSD. Over their lifetime the respective values were $548(22 \%), 637(25 \%)$ and 161 (6\%). Substantiated abuse was significantly associated with lifetime depressive disorder, but not depression in the previous 12 months. Of the subtypes, emotional abuse and neglect showed the strongest association with lifetime depression, as well as symptoms over the previous 12 months, as did multiple types of substantiation (Table 2).

In terms of anxiety, both 12-month and lifetime prevalence were associated with substantiated abuse (Table 3). In terms of the subtypes, emotional abuse and neglect again showed the strongest association. Here too, multiple types of substantiated abuse, as well as more than one substantiated event were associated with anxiety.

Of all the disorders, PTSD showed the strongest association with substantiated abuse (Table 4). For this disorder, almost all the subtypes (including sexual abuse), multiple types and more than one event were associated with PTSD. The one exception was physical abuse and PTSD in the previous 12 months.

\section{Sensitivity analyses of the results for any substantiated abuse}

The results were no longer significant when restricted to the small number of individuals whose cases were substantiated by 5 years 
Table 2 Any depressive disorder odds ratios (Composite International Diagnostic Interview-Auto version, DSM-IV) - additional adjustment for 21-year mediating/modifying variables ${ }^{a}$

\begin{tabular}{|c|c|c|c|c|c|c|}
\hline & \multicolumn{3}{|c|}{ Any depressive disorder (past 12 months) } & \multicolumn{3}{|c|}{ Any depressive disorder (lifetime) } \\
\hline & Crude OR & Adjusted OR & $P$ & Crude OR & Adjusted OR & $P$ \\
\hline No maltreatment & 1.0 & & & 1.0 & & \\
\hline Any substantiation & $1.56(1.05-2.33)$ & $1.56(0.92-2.65)$ & 0.09 & $1.56(1.14-2.13)$ & $1.56(1.03-2.36)$ & 0.04 \\
\hline Physical abuse & $1.56(0.72-3.35)$ & $1.34(0.58-3.06)$ & 0.48 & $1.38(0.74-2.58)$ & $1.09(0.56-2.12)$ & 0.79 \\
\hline Emotional abuse & $2.12(1.11-4.05)$ & $2.23(1.14-4.34)$ & 0.02 & $1.85(1.07-3.18)$ & $1.75(1.00-3.10)$ & 0.05 \\
\hline Neglect & $2.46(1.24-4.87)$ & $2.58(1.27-5.26)$ & 0.01 & $1.96(1.08-3.55)$ & $1.94(1.04-3.64)$ & 0.04 \\
\hline Sexual abuse & $2.17(0.99-4.78)$ & $1.75(0.78-3.94)$ & 0.17 & $2.86(1.51-5.43)$ & $2.15(1.11-4.16)$ & 0.02 \\
\hline More than one substantiation event & $1.36(0.96-1.92)$ & $1.32(0.91-1.89)$ & 0.14 & $1.40(1.06-1.85)$ & $1.30(0.98-1.74)$ & 0.07 \\
\hline Emotional abuse + neglect & $1.75(0.97-3.15)$ & $1.64(0.89-3.020$ & 0.11 & $1.82(1.14-2.92)$ & $1.81(1.11-2.96)$ & 0.018 \\
\hline Multiple abuse types & $2.27(1.18-4.43)$ & $2.33(1.19-4.58)$ & 0.014 & $2.16(1.25-3.73)$ & $1.99(1.12-3.54)$ & 0.018 \\
\hline
\end{tabular}

\begin{tabular}{|c|c|c|c|c|c|c|}
\hline & \multicolumn{3}{|c|}{ Any anxiety disorder (past 12 months) } & \multicolumn{3}{|c|}{ Any anxiety disorder (lifetime) } \\
\hline & Crude OR & Adjusted OR & $P$ & Crude OR & Adjusted OR & $P$ \\
\hline No maltreatment & 1.0 & & & 1.0 & & \\
\hline Any substantiation & $2.44(1.80-3.31)$ & $2.28(1.51-3.45)$ & $<0.001$ & $2.26(1.69-3.03)$ & $1.95(1.30-2.91)$ & 0.001 \\
\hline Physical abuse & $2.29(1.28-4.09)$ & $1.90(1.02-3.56)$ & 0.04 & $1.90(1.01-3.34)$ & $1.50(0.86-2.92)$ & 0.14 \\
\hline Emotional abuse & $3.05(1.81-5.12)$ & $3.04(1.76-5.31)$ & $<0.001$ & $2.79(1.68-4.66)$ & $2.68(1.55-4.63)$ & $<0.001$ \\
\hline Neglect & $3.88(2.19-6.86)$ & $4.25(2.29-7.78)$ & $<0.001$ & $2.95(1.67-5.20)$ & $3.01(1.63-5.58)$ & $<0.001$ \\
\hline Sexual abuse & $3.21(1.70-6.05)$ & $2.18(1.12-4.23)$ & 0.02 & $2.76(1.47-5.17)$ & $1.80(0.93-3.47)$ & 0.08 \\
\hline More than one substantiation event & $1.82(1.39-2.37)$ & $1.69(1.27-2.25)$ & $<0.001$ & $1.68(1.30-2.18)$ & $1.52(1.15-2.01)$ & 0.004 \\
\hline Emotional abuse + neglect & $2.68(1.69-4.24)$ & $2.78(1.70-4.54)$ & $<0.001$ & $2.30(1.47-3.60)$ & $2.27(1.40-3.67)$ & 0.001 \\
\hline Multiple abuse types & $3.09(1.82-5.27)$ & $2.93(1.66-5.19)$ & $<0.001$ & $2.49(1.47-4.22)$ & $2.22(1.26-3.91)$ & 0.006 \\
\hline
\end{tabular}

old $(n=61)$. The only exceptions were for the 12 -month prevalence of anxiety (odds ratio $(\mathrm{OR})=2.19,95 \% \mathrm{CI} 1.07-4.84, P=0.03$ ) and PTSD (OR $=3.35,95 \%$ CI $1.27-9.16, P=0.02)$, as well as the lifetime prevalence of the latter disorder $(\mathrm{OR}=3.38,95 \% \mathrm{CI} 1.39-8.19, P=$ $0.007)$.

The addition of a propensity score to the model, taking into consideration baseline covariates across the entire cohort, did not alter our results, with the exception that there was no longer a significant association with internalising behaviour in models with, and without, the 21-year follow-up variables (Supplementary Table 3).

\section{Discussion}

\section{Main findings}

There is limited population-based research on whether poor health outcomes are more common among those exposed to childhood maltreatment. This study adds to the literature by accessing a population sample, measurement of prospectively substantiated child abuse and consideration of different types of child maltreatment. A further strength is that it controls for a wide range of confounders/covariates concerning both maternal and child sociodemographics. Accordingly, the findings may provide an empirical basis for relevant healthcare policy improvement and for integrated, developmentally appropriate child and adult health services.

We found that depressive symptoms on the CES-D, as well as internalising and externalising behaviour, were strongly associated with substantiated abuse in all forms, except sexual abuse. The results for the subset of the sample who completed the CIDI-Auto were less clear. Anxiety, especially PTSD, showed the strongest association whereas the findings for depressive disorder were equivocal. However, across all diagnostic categories, emotional abuse and neglect, as well as multiple types of abuse, showed a consistent association.

\section{Comparison with findings from other studies}

Much research focuses on traumatic childhood experiences such as physical or sexual abuse, rather than emotional abuse and neglect. ${ }^{33,34}$ For instance, self-reported physical abuse has been found to predict both depression and anxiety in middle-aged men and women. ${ }^{17}$ However, there is now growing evidence of the adverse effects of emotional abuse and neglect. Both can alter neurobiological development in early life, which can in turn negatively affect physical, cognitive, emotional and social growth, leading to psychological, behavioural and learning problems that persist in later life. ${ }^{15}$ Many adult diseases are related to developmental and biological disruptions in childhood possibly through cumulative damage over time or direct biological effects during sensitive developmental periods. ${ }^{15}$ For instance emotional abuse and neglect may alter the development of brain reward and oxytocin systems in children leading to impaired parental care giving in the subsequent generation. ${ }^{35}$ In addition, subtle emotional maltreatment because of psychologically unavailable parents may be associated with poor attachment, behavioural problems and academic difficulties. ${ }^{21}$ The situation is aggravated by self-medication of subsequent distress with misuse of alcohol, prescription medication, tobacco or other drugs. ${ }^{21}$

In one review of 124 studies, emotional abuse increased the risk of depression by an odds ratio of 3.06, whereas physical abuse increased the risk of depression by only half that amount. ${ }^{15}$ Similarly, childhood emotional maltreatment was more closely related to depression severity than sexual or physical abuse. ${ }^{15}$ 
Table 4 Any post-traumatic stress disorder odds ratios (Composite International Diagnostic Interview-Auto version, DSM-IV) ${ }^{a}$

\begin{tabular}{|c|c|c|c|c|c|c|}
\hline & \multicolumn{3}{|c|}{ Any post-traumatic stress disorder (last 12 months) } & \multicolumn{3}{|c|}{ Any post-traumatic stress disorder (lifetime) } \\
\hline & Crude OR & Adjusted OR & $P$ & Crude OR & Adjusted OR & $P$ \\
\hline No maltreatment & 1.0 & & & 1.0 & & \\
\hline Any substantiation & $3.79(2.38-6.04)$ & $3.05(1.65-5.65)$ & $<0.001$ & $4.03(2.71-6.00)$ & $3.38(2.00-5.70)$ & $<0.001$ \\
\hline Physical abuse & $2.48(0.96-6.38)$ & $2.26(0.86-6.05)$ & 0.10 & $2.29(1.33-6.26)$ & $2.54(1.12-5.72)$ & 0.0025 \\
\hline Emotional abuse & $3.67(1.70-7.94)$ & $3.58(1.59-8.06)$ & 0.002 & $5.02(2.69-9.36)$ & $4.76(2.45-8.16)$ & $<0.001$ \\
\hline Neglect & $3.99(1.75-9.12)$ & $3.89(1.61-9.38)$ & 0.003 & $3.11(1.43-6.78)$ & $2.78(1.22-6.39)$ & 0.016 \\
\hline Sexual abuse & $7.01(3.24-15.14)$ & $5.58(2.48-12.60)$ & $<0.001$ & $6.11(2.99-12.51)$ & 4.38 (2.06-9.29) & $<0.001$ \\
\hline More than one substantiation event & $2.26(1.54-3.31)$ & $2.17(1.45-3.25)$ & $<0.001$ & $2.45(1.77-3.39)$ & $2.30(1.62-3.26)$ & $<0.001$ \\
\hline Emotional abuse + neglect & $3.36(1.68-6.72)$ & $3.36(1.67-7.00)$ & 0.001 & $4.03(2.27-7.15)$ & $3.93(2.13-7.26)$ & $<0.001$ \\
\hline Multiple abuse types & $4.54(2.16-9.53)$ & $4.19(1.90-9.23)$ & $<0.001$ & $4.85(2.55-9.24)$ & $4.23(2.12-8.44)$ & $<0.001$ \\
\hline
\end{tabular}

These findings were confirmed in a recent systematic review and meta-analysis, although most of the data came from retrospective cross-sectional studies or longitudinal designs that relied on selfreported abuse. ${ }^{36}$ Our results, based on prospectively gathered substantiated reports, suggest that neglect and emotional abuse needs to be given at least as much attention as physical and sexual abuse as potential sources of long-term psychological dysfunction.

By contrast, sexual abuse showed a far weaker association. There are several possible explanations. Sexual abuse may be underreported because of inconsistent definitions, ${ }^{37}$ secrecy $^{38}$ and stigma. ${ }^{32}$ Conversely, the nature and severity of sexual abuse, ${ }^{39}$ may mean that it is more likely to be reported and attract an agency response before leading to long-term disorders. In addition, the incidence of sexual abuse was lower than that of the other maltreatment types, and this may have affected the statistical power to detect significant associations. Importantly, sexual abuse was included in some of the other definitions that did show a significant association.

PTSD was the one disorder that did show an association with sexual abuse. This is consistent with our earlier paper comparing self-reported to agency-notified abuse (as opposed to substantiated abuse as reported in the current paper). ${ }^{32}$ It highlights that although PTSD is less common than depression or anxiety, the diagnosis has particular relevance as a relatively specific outcome following childhood sexual abuse. Although this association is widely reported in the literature on PTSD and sexual abuse, findings are again almost completely based on cross-sectional self-report studies, ${ }^{40}$ and not on longitudinal follow-up of prospective agency-substantiated abuse.

\section{Limitations}

There are several limitations to the study. These findings cannot be generalised to twins and triplets as the small number born to MUSP mothers were excluded from the longitudinal cohort. The overall follow-up rate at 21 years old was $52.4 \%$ (3778 participants). Although acceptable for a long-term birth cohort of over 20 years' duration, only two-thirds of these participants $(n=2508)$ completed the CIDI-Auto interview. This is why we have highlighted the results from the CES-D and YASR. In addition, attrition was greater among those experiencing social disadvantage. However, our findings were unchanged when we used propensity score analysis that took into consideration baseline covariates across the entire at-risk cohort. Importantly, studies of attrition in other birth cohorts suggest that those lost to follow-up broadly have the outcomes that would be expected given their baseline characteristics. ${ }^{41}$ Analysis of the MUSP cohort over three decades, and with various statistical methods, lends support to this observation. ${ }^{22}$

The use of legally defined cases is likely to have underestimated the true prevalence of childhood maltreatment, and may account for the weak associations, particularly for maltreatment substantiation by 5 years old, as well as sexual abuse. ${ }^{37}$ Our findings are therefore likely to be conservative estimates of the true association between child maltreatment and psychiatric morbidity in early adulthood. In addition, the low numbers necessitated the use of broad definitions for the DSM-IV diagnoses that may have disguised important differences within the categories. Finally, the reasons for reports to agencies reflect a number of factors in addition to whether the child experienced maltreatment.

\section{Implications}

In conclusion, our results highlight the importance of emotional abuse and neglect as a cause of a wide range of adverse psychological outcomes in early adulthood. They also suggest variations in the long-term effects of different types of abuse, with both physical and sexual abuse having a stronger association with anxiety, particularly PTSD. Greater awareness of these factors may inform interventions, particularly primary and secondary prevention, with the aim of shifting to a public health approach, rather than one focused solely on immediate safety.

Steve Kisely, MD, PhD, DMedRes (D), Professor, School of Medicine, University of Queensland, Princess Alexandra Hospital, Australia and Departments of Psychiatry, Community Health and Epidemiology, Dalhousie University, Canada; Amanuel Alemu Abajobir, MPH, Researcher, School of Public Health, The University of Queensland, Australia; Ryan Mills, MBBS(Hons), FRACP, MPH, Senior Lecturer, School of Medicine, University of Queensland, Princess Alexandra Hospital, Australia; Lane Strathearn, MBBS, PhD, FRACP, Professor, Department of Paediatrics, Developmental and Behavioural Paediatrics, University of Iowa, USA; Alexandra Clavarino, BSocWk, BA(Hons1), PhD, Associate Professor, The School of Pharmacy, Pharmacy Australia Centre of Excellence, The University of Queensland, Australia; Jake Moses Najman, PhD, FASSA, Professor, School of Medicine, Princess Alexandra Hospital, School of Social Sciences, The University of Queensland and Queensland Alcohol and Drug Research and Education Centre, The University of Queensland, Australia

Correspondence: Steve Kisely, School of Medicine I, The University of Queensland, Level 4, Building 1, Princess Alexandra Hospital, Ipswich Road, Woolloongabba, QLD 4102, Australia.Email: s.kisely@uq.edu.au

First received 8 Jun 2018, accepted 26 Aug 2018

\section{Supplementary material}

Supplementary material is available online at https://doi.org/10.1192/bjp.2018.207.

\section{References}

1 Fry D, McCoy A, Swales D. The consequences of maltreatment on children's lives: a systematic review of data from the East Asia and Pacific Region. Trauma Violence Abuse 2012; 13: 209-33.

2 Wekerle C, Wolfe DA, Hawkins D, Pittman A-L, Glickman A, Lovald BE. Childhood maltreatment, posttraumatic stress symptomatology, and 
adolescent dating violence: considering the value of adolescent perceptions of abuse and a trauma mediational model. Dev Psychopathol 2001; 13: 847-71.

3 Chapman DP, Whitfield CL, Felitti VJ, Dube SR, Edwards VJ, Anda RF. Adverse childhood experiences and the risk of depressive disorders in adulthood. J Affect Disord 2004; 82: 217-25.

4. Widom CS, Raphael KG, DuMont KA. The case for prospective longitudinal studies in child maltreatment research: commentary on Dube, Williamson Thompson, Felitti, and Anda (2004). Child Abuse Neg/ 2004; 28: 715-22.

5 Fergusson DM, Horwood LJ, Woodward L. The stability of child abuse reports: a longitudinal study of the reporting behaviour of young adults. Psychol Med 2000; 30: 529-44.

6 Arata CM, Langhinrichsen-Rohling J, Bowers D, O'Brien N. Differential correlates of multi-type maltreatment among urban youth. Child Abuse Neg/ 2007; 31: 393-415.

7 Thornberry TP, Matsuda M, Greenman SJ, Augustyn MB, Henry KL, Smith CA et al. Adolescent risk factors for child maltreatment. Child Abuse Neg/ 2014; 38 706-22.

8 Soares AL, Howe LD, Matijasevich A, Wehrmeister FC, Menezes AM Goncalves H. Adverse childhood experiences: prevalence and related factors in adolescents of a Brazilian birth cohort. Child Abuse Neg/ 2016; 51: 21-30.

9 Dekel S, Bonanno GA. Changes in trauma memory and patterns of posttraumatic stress. Psychol Trauma 2013; 5: 26.

10 Trickett PK, Noll JG, Putnam FW. The impact of sexual abuse on female development: lessons from a multigenerational, longitudinal research study. Dev Psychopathol 2011; 23: 453-76.

11 Gilbert R, Widom CS, Browne K, Fergusson D, Webb E, Janson S. Burden and consequences of child maltreatment in high-income countries. Lancet 2009; 373: 68-81.

12 Spataro J, Mullen PE, Burgess PM, Wells DL, Moss SA. Impact of child sexual abuse on mental health: prospective study in males and females. $\mathrm{Br} J$ Psychiatry 2018; 184: 416-21.

13 Baiden P, Stewart SL, Dunnen W. Childhood abuse and cannabis use among adolescents with mental health needs in Ontario, Canada. J Subst Use 2014; 19: 18-24.

14 Aas M, Etain B, Bellivier F, Henry C, Lagerberg T, Ringen A, et al. Additive effects of childhood abuse and cannabis abuse on clinical expressions of bipolar disorders. Psychol Med 2014; 44: 1653-62.

15 Norman RE, Byambaa M, De R, Butchart A, Scott J, Vos T. The long-term health consequences of child physical abuse, emotional abuse, and neglect: a systematic review and meta-analysis. PLOS Med 2012; 9: e1001349.

16 Doidge JC, Higgins DJ, Delfabbro P, Segal L. Risk factors for child maltreatment in an Australian population-based birth cohort. Child Abuse Neg/ 2017; 64: 47-60.

17 Springer KW, Sheridan J, Kuo D, Carnes M. Long-term physical and mental health consequences of childhood physical abuse: results from a large population-based sample of men and women. Child Abuse Neg/ 2007: 31: 517-30.

18 Breslau N, Koenen KC, Luo Z, Agnew-Blais J, Swanson S, Houts RM, et al. Childhood maltreatment, juvenile disorders and adult post-traumatic stress disorder: a prospective investigation. Psychol Med 2014; 44: 1937-45.

19 Sidebotham $\mathrm{P}$, Heron J, Team AS. Child maltreatment in the 'children of the nineties': a cohort study of risk factors. Child Abuse Neg/ 2006; 30: 497-522.

20 Scott KM, Smith DR, Ellis PM. Prospectively ascertained child maltreatment and its association with DSM-IV mental disorders in young adults. Arch Gen Psychiatry 2010; 67: 712-9.

21 Mills R, Scott J, Alati R, O'Callaghan M, Najman JM, Strathearn L. Child maltreatment and adolescent mental health problems in a large birth cohort. Child Abuse Neg/ 2013; 37: 292-302.

22 Najman JM, Bor W, O'Callaghan M, Williams GM, Aird R, Shuttlewood G. Cohort profile: the Mater-University of Queensland Study of Pregnancy (MUSP). Int J Epidemiol 2005; 34: 992-7.
23 Lau AS, Leeb RT, English D, Graham JC, Briggs EC, Brody KE, et al. What's in a name? A comparison of methods for classifying predominant type of maltreatment. Child Abuse Negl 2005; 29: 533-51.

24 Nicholls SG, Quach P, von Elm E, Guttmann A, Moher D, Petersen I, et al. The reporting of studies conducted using observational routinely-collected health data (RECORD) statement: methods for arriving at consensus and developing reporting guidelines. PLoS One 2015; 10: e0125620.

25 Strathearn L, Mamun AA, Najman JM, O'Callaghan MJ. Does breastfeeding protect against substantiated child abuse and neglect? A 15-year cohort study. Pediatrics 2009; 123: 483-93.

26 Lewinsohn PM, Seeley JR, Roberts RE, Allen NB. Center for Epidemiologic Studies Depression Scale (CES-D) as a screening instrument for depression among community-residing older adults. Psychol Aging 1997; 12: 277.

27 Achenbach TM. Manual for the Youth Self-Report and 1991 Profile. Department of Psychiatry, University of Vermont Burlington, 1991.

28 American Psychiatric Association. Diagnostic and Statistical Manual of Mental Disorder (4th edn) (DSM-IV). APA, 1994.

29 Peters L, Clark D, Carroll F. Are computerized interviews equivalent to human interviewers? CIDI-Auto versus CIDI in anxiety and depressive disorders. Psychol Med 1998; 28: 893-901.

30 Abajobir AA, Kisely S, Scott JG, Williams G, Clavarino A, Strathearn L, et al. Childhood maltreatment and young adulthood hallucinations, delusional experiences, and psychosis: a longitudinal study. Schizophr Bull 2017; 43 1045-55.

31 Goodman JS, Blum TC. Assessing the non-random sampling effects of subject attrition in longitudinal research. J Manag 1996; 22: 627-52.

32 Mills R, Kisely S, Alati R, Strathearn L, Najman J. Self-reported and agencynotified child sexual abuse in a population-based birth cohort. J Psychiatr Res 2016; 74: 87-93.

33 Dube SR, Anda RF, Whitfield CL, Brown DW, Felitti VJ, Dong M, et al. Long-term consequences of childhood sexual abuse by gender of victim. Am J Prev Med 2005; 28: 430-8.

34 Lansford J, Dodge K, Pettit G, Bates J, Crozier J, Kaplow J. Long-term effects of early child physical maltreatment on psychological, behavioral, and academic problems in adolescence: a 12-year prospective study. Arch Pediatr Adolesc Med 2002; 156: 824-30.

35 Strathearn L. Maternal neglect: oxytocin, dopamine and the neurobiology of attachment. J Neuroendocrinol 2011; 23: 1054-65.

36 Nelson J, Klumparendt A, Doebler P, Ehring T. Childhood maltreatment and characteristics of adult depression: meta-analysis. Br J Psychiatry 2017; 210: 96-104.

37 Martin EK, Silverstone PH. How much child sexual abuse is 'below the surface,' and can we help adults identify it early? Front Psychiatry 2013; 4: 58.

38 Polonko KA. Exploring assumptions about child neglect in relation to the broader field of child maltreatment. J Health Hum Serv Adm 2006; 29 260-84.

39 Hahm HC, Lee Y, Ozonoff A, Van Wert MJ. The impact of multiple types of child maltreatment on subsequent risk behaviors among women during the transition from adolescence to young adulthood. J Youth Adolesc 2010; 39 528-40.

40 Hetzel MD, McCanne TR. The roles of peritraumatic dissociation, child physical abuse, and child sexual abuse in the development of posttraumatic stress disorder and adult victimization. Child Abuse Neg/ 2005; 29: 915-30.

41 Wolke D, Waylen A, Samara M, Steer C, Goodman R, Ford T, et al. Selective drop-out in longitudinal studies and non-biased prediction of behaviou disorders. Br J Psychiatry 2009; 195: 249-56. 